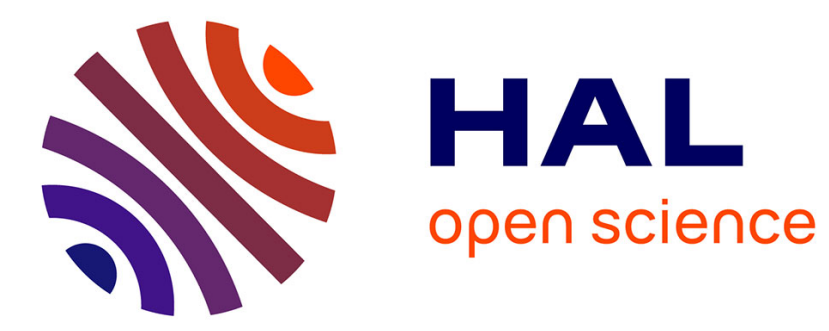

\title{
Two-Component Mixed and Patterned Films on Carbon Surfaces through the Photografting of Arylazides
}

\author{
Andrew Gross, Samuel S C Yu, Alison Downard
}

\section{To cite this version:}

Andrew Gross, Samuel S C Yu, Alison Downard. Two-Component Mixed and Patterned Films on Carbon Surfaces through the Photografting of Arylazides. Langmuir, 2010, 26 (10), pp.7285-7292. 10.1021/la904442u . hal-03016885

\section{HAL Id: hal-03016885 https://hal.science/hal-03016885}

Submitted on 20 Nov 2020

HAL is a multi-disciplinary open access archive for the deposit and dissemination of scientific research documents, whether they are published or not. The documents may come from teaching and research institutions in France or abroad, or from public or private research centers.
L'archive ouverte pluridisciplinaire HAL, est destinée au dépôt et à la diffusion de documents scientifiques de niveau recherche, publiés ou non, émanant des établissements d'enseignement et de recherche français ou étrangers, des laboratoires publics ou privés. 


\title{
Langmuir
}

\author{
pubs.acs.org/Langmuir
}

(C) XXXX American Chemical Society

\section{Two-Component Mixed and Patterned Films on Carbon Surfaces through the Photografting of Arylazides}

\author{
Andrew J. Gross, Samuel S. C. Yu, ${ }^{\dagger}$ and Alison J. Downard* \\ MacDiarmid Institute for Advanced Materials and Nanotechnology, Department of Chemistry, University of \\ Canterbury, Private Bag 4800, Christchurch 8140, New Zealand. 'Present address: Izon Science Ltd, \\ P.O. Box 20189, Bishopdale, Christchurch 8543, New Zealand.
}

Received November 23, 2009. Revised Manuscript Received January 22, 2010

\begin{abstract}
Organic films have been grafted to glassy carbon surfaces by the photolysis of arylazides. Atomic force microscopy and electrochemical measurements reveal that the films are loosely packed. The methodology was expanded to prepare two-component thin films incorporating either a reactive tether species and a nonreactive background film or two different reactive tethers. Strategies were developed to generate both continuous mixed films and surfaces presenting patterns of two components. For patterning, the arylazide derivative was grafted onto previously modified glassy carbon surfaces. In this case, the first modification step is not limited to photografting, which increases the scope of the methods. For all grafted surfaces, the reactivity of tether species was confirmed by coupling electroactive targets to the tethers, followed by electrochemical monitoring. The ease of preparing surfaces with spatially controlled functionality offers promise for the design of sensing platforms on graphitic carbon substrates.
\end{abstract}

\section{Introduction}

Control of the composition of the sensing surface is an important aspect of chemical and biosensor design and implementation. Surface immobilization of the molecular recognition species can facilitate integration of the sensing element with the transducer and incorporation of these into a device. Manipulation of the chemical and physical properties of the surface can also address unwanted interactions at the interface such as nonspecific binding of the analyte and the adsorption of components of the sample matrix. The development of modification methods suitable for application to sensing surfaces is thus an active area of research.

Conductive carbon has attractive properties for sensor construction because it is an easy-to-handle and usually low-cost material with high mechanical stability. ${ }^{1}$ Importantly, the surface of carbon can be readily modified by reactions involving the generation of solution-based organic radicals that attack the surface, resulting in the formation of $\mathrm{C}-\mathrm{C}$ or $\mathrm{C}-\mathrm{N}$ covalent bonds between the modifier and the surface. ${ }^{2-4}$ The best-known examples of such reactions are the reduction of aryldiazonium salts to generate the corresponding aryl radical ${ }^{5,6}$ and the oxidation of primary amines to yield N-centered radicals. ${ }^{7}$ In general, these radical-based reactions result in carbon surfaces modified

*To whom correspondence should be addressed. Tel: 64-3-3642501. Fax: 64-3-3642110. E-mail: alison.downard@canterbury.ac.nz.

(1) McCreery, R. L. In Electroanalytical Chemistry; Bard, A. J., Ed.; Dekker: New York, 1991; Vol. 17

(2) Barriere, F.; Downard, A. J. J. Solid State Electrochem. 2008, 12, 1231-1244.

(3) Downard, A. J. Electroanalysis 2000, 12, 1085-1096.

(4) Pinson, J.; Podvorica, F. Chem. Soc. Rev. 2005, 34, 429-439.

(5) Allongue, P.; Delamar, M.; Desbat, B.; Fagebaume, O.; Hitmi, R.; Pinson, J.; Saveant, J.-M. J. Am. Chem. Soc. 1997, 119, 201-207.

(6) Delamar, M.; Hitmi, R.; Pinson, J.; Saveant, J. M. J. Am. Chem. Soc. 1992, 114, 5883-5884.

(7) Barbier, B.; Pinson, J.; Desarmot, G.; Sanchez, M. J. Electrochem. Soc. 1990, 137, 1757-1764.

(8) Anariba, F.; DuVall, S. H.; McCreery, R. L. Anal. Chem. 2003, 75, 38373844.

(9) Brooksby, P. A.; Downard, A. J. Langmuir 2004, 20, 5038-5045.

(10) Brooksby, P. A.; Downard, A. J. J. Phys. Chem. B 2005, 109, 8791-8798. with disorganized multilayer organic coatings, less than $10 \mathrm{~nm}$ thick, ${ }^{8-11}$ that exhibit excellent thermal, mechanical, and chemical stability and are stable over a relatively wide potential range. ${ }^{5,12,13}$

Although redox methods have been most widely investigated, there are some reports of photolytic approaches for the covalent attachment of organic modifiers to graphitic carbon surfaces. The photolysis of carbon substrates in solutions of alkenes and alkynes or after spin coating from the same solutions results in grafting of monolayer films to the substrate. ${ }^{14-16}$ Alkenes and alkynes do not absorb at the wavelength used for these reactions, and hence the activation of the substrate is implicated in the grafting reaction. ${ }^{17}$ In contrast, when irradiated with UV light, azide and diazirine derivatives are well known to eliminate dinitrogen to generate reactive nitrenes and carbenes, respectively. Arylazides in particular have been widely used for photoaffinity labeling ${ }^{18}$ and for the preparation of protein chips. ${ }^{19}$ Nitrenes can insert into $\mathrm{O}-\mathrm{H}, \mathrm{N}-\mathrm{H}$, and $\mathrm{C}-\mathrm{H}$ bonds and also undergo $\mathrm{C}=\mathrm{C}$ addition reactions with neighboring molecules, ${ }^{20}$ giving several pathways for covalent grafting to a carbon surface. These reactions have been developed by Kuhr and coworkers who used azide and diazirine derivatives of biotin

(11) Kariuki, J. K.; McDermott, M. T. Langmuir 2001, 17, 5947-5951.

(12) D'Amours, M.; Belanger, D. J. Phys. Chem. B 2003, 107, 4811-4817.

(13) Delamar, M.; Desarmot, G.; Fagebaume, O.; Hitmi, R.; Pinson, J.; Saveant, J. M. Carbon 1997, 35, 801-807.

(14) Lasseter, T. L.; Cai, W.; Hamers, R. J. Analyst 2004, 129, 3-8.

(15) Sun, B.; Colavita, P. E.; Kim, H.; Lockett, M.; Marcus, M. S.; Smith, L. M.; Hamers, R. J. Langmuir 2006, 22, 9598-9605.

(16) Yu, S. S. C.; Downard, A. J. Langmuir 2007, 23, 4662-4668.

(17) Colavita, P. E.; Sun, B.; Wang, X. Y.; Hamers, R. J. J. Phys. Chem. C 2009, $113,1526-1535$

(18) Fleming, S. A. Tetrahedron 1995, 51, 12479-12520

(19) Jonkheijm, P.; Weinrich, D.; Schroder, H.; Niemeyer, C. M.; Waldmann, H. Angew. Chem., Int. Ed. 2008, 47, 9618-9647.

(20) Nitrenes; Lwowski, W., Ed.; Interscience: New York, 1970.

(21) Nowall, W. B.; Dontha, N.; Kuhr, W. G. Biosens. Bioelectron. 1998, 13, $1237-1244$.

(22) Nowall, W. B.; Wipf, D. O.; Kuhr, W. G. Anal. Chem. 1998, 70, 2601-2606.

(23) Dontha, N.; Nowall, W. B.; Kuhr, W. G. Anal. Chem. 1997, 69, 2619-2625. 
(photobiotin) to generate micrometer-scale patterns of biotin on glassy carbon (GC) surfaces. ${ }^{21-26}$

Our goal is to develop simple, versatile, and patternable methods for the modification of planar graphitic carbon substrates. To our knowledge, the photolysis of azides, other than the biotin derivative (photobiotin), ${ }^{21-27}$ has not been used for the preparation of such surfaces. The thermally induced decomposition of azides to nitrenes has been successfully applied to the functionalization of carbon nanotube sidewalls ${ }^{28-31}$ and, most recently, graphene. ${ }^{32,33}$ However, photolytic methods are more easily adapted to surface patterning. This approach was recently demonstrated with the photopatterning of perfluoroazide derivatives onto carbon nanotube forests for the control of surface wettability. ${ }^{34}$

In this work, we explore the photolytic modification of glassy carbon and glassy carbon-like thin films (pyrolyzed photoresist films, PPF $)^{35}$ with the arylazide derivatives shown in Figure 1. Mixed films were prepared by the photolysis of a spin-coated solution containing two arylazide derivatives, and we also prepared two-component films by photografting arylazide derivatives to preformed modified surfaces. By expanding the latter strategy, arylazide derivatives were patterned onto film-coated surfaces by irradiation through a mask.

\section{Experimental Section}

Materials and Reagents. 4-Azidophenyl isothiocyanate $\left(\mathrm{ITC}_{\mathrm{A}}\right)$, 4-azidoaniline hydrochloride $\left(\mathrm{AP}_{\mathrm{A}}\right)$, 4-nitrobenzoic hydrazide, $O$-( $N$-succinimidyl)- $N, N, N^{\prime}, N^{\prime}$-tetramethyluronium tetrafluoroborate (TSTU) and $N, N$-diisopropyl ethylamine (DIPEA) (all from Sigma-Aldrich, purity $\geq 97 \%$ ), 4-nitrobenzoyl chloride $(>98 \%)$ and ethylenediamine $(>99 \%)$ (both from MerckSchuchardt), methoxy-poly(ethylene glycol)-amine (PEG) (>99\%, Laysan Bio), triethylene glycolamine (TEG, >97\%, Prime Organics), sodium nitrite (98\%, Panreal), and sodium citrate and 4-nitrobenzoic acid (both from BDH, >99\%) were used as received. Dichloromethane (DCM) and $N, N$-dimethylformamide (DMF) (both from Scharlau Chemie, 99.9\%), acetone (99.5\%, Mallinckrodt Baker), and ethanol (EtOH, 99.9\%, Merck) were used as received. Acetonitrile (ACN, 99.9\%, BDH) was dried over calcium hydride for $>2$ days and refluxed under $\mathrm{N}_{2}$ for at least $2 \mathrm{~h}$ prior to distilling in a $\mathrm{N}_{2}$ atmosphere. Aqueous solutions were prepared using Millipore Milli-Q water $(>18 \mathrm{M} \Omega \mathrm{cm})$. The tetrafluoroborate salts of the 4-nitrobenzenediazonium cation $\left(\mathrm{NP}_{\mathrm{D}}\right)$ and the 4-carboxybenzenediazonium cation $\left(\mathrm{CB}_{\mathrm{D}}\right)$ were synthesized from their arylamine precursors (Aldrich) using standard procedures. ${ }^{36}$ 4-Azidonitrobenzene $\left(\mathrm{NP}_{\mathrm{A}}\right)$ was synthesized by adding 1 equiv of sodium azide

(24) Dontha, N.; Nowall, W. B.; Kuhr, W. G. J. Pharm. Biomed. Anal. 1999, 19 , $83-91$ 2563.

(25) Brooks, S. A.; Ambrose, W. P.; Kuhr, W. G. Anal. Chem. 1999, 71, 2558-

(26) Brooks, S. A.; Dontha, N.; Davis, C. B.; Stuart, J. K.; O’Neil, G.; Kuhr, W. G. Anal. Chem. 2000, 72, 3253-3259.

(27) Wilde, L. M.; Farace, G.; Roberts, C. J.; Davies, M. C.; Sanders, G. H. W.; Tendler, S. J. B.; Williams, P. M. Analyst 2001, 126, 195-198.

(28) Gao, C.; He, H.; Zhou, L.; Zheng, X.; Zhang, Y. Chem. Mater. 2009, 21, $360-370$.

(29) Holzinger, M.; Abraha, J.; Whelan, P.; Graupner, R.; Ley, L.; Hennrich, F.; Kappes, M.; Hirsch, A. J. Am. Chem. Soc. 2003, 125, 8566-8580.

(30) Holzinger, M.; Steinmetz, J.; Samaille, D.; Glerup, M.; Paillet, M.; Bernier, P.; Ley, L.; Graupner, R. Carbon 2004, 42, 941-947.

(31) Holzinger, M.; Vostrowsky, O.; Hirsch, A.; Hennrich, F.; Kappes, M.

Weiss, R.; Jellen, F. Angew. Chem., Int. Ed. 2001, 40, 4002-4005.

(32) Liu, L. H.; Yan, M. D. Nano Lett. 2009, 9, 3375-3378.

(33) Choi, J.; Kim, K.-j.; Kim, B.; Lee, H.; Kim, S. J. Phys. Chem. C 2009, 113, 9433-9435.

(34) Pastine, S. J.; Okawa, D.; Kessler, B.; Rolandi, M.; Llorente, M.; Zettl, A.; Frechet, J. M. J. J. Am. Chem. Soc. 2008, 130, 4238-4239.

(35) Ranganathan, S.; McCreery, R. L. Anal. Chem. 2001, 73, 893-900.

(36) Saunders, K. H.; Allen, R. L. M. Aromatic Diazo Compounds, 3rd ed.; Edward Arnold: London, 1985

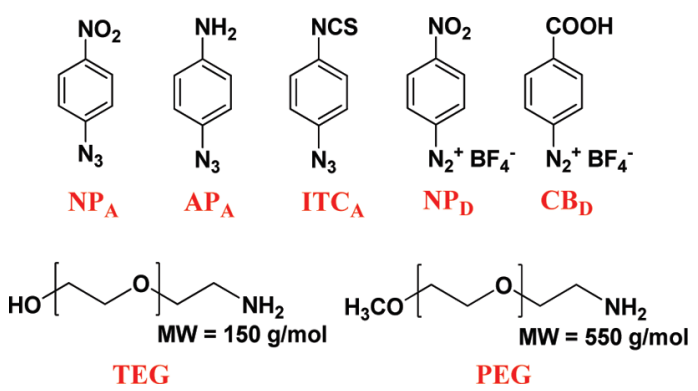

Figure 1. Arylazides used for photografting and aryldiazonium salts and amines used for electrografting.

$(99 \%$, Fisons) to an aqueous solution of the 4-nitrobenzenediazonium salt with cooling in an ice bath. After being stirred for $30 \mathrm{~min}$, the solution was filtered and the precipitated product was washed with cold water and acetonitrile $(\mathrm{ACN})$, suction dried, and stored in the dark. The preparation and drying of $\left[\mathrm{Bu}_{4} \mathrm{~N}\right] \mathrm{BF}_{4}$ have been described previously. ${ }^{9}$ All synthesized salts and arylazides were stored under vacuum and in the dark. Citrate-capped gold nanoparticles with a diameter of approximately $13 \mathrm{~nm}$ were prepared from hydrogen tetrachloroaurate(III) hydrate $(99.9 \%$, Strem Chemicals) using the method of Natan and co-workers. ${ }^{37}$

Carbon Surface Preparation. PPF surfaces were fabricated as described previously ${ }^{9}$ and sonicated in ACN for 5 min before modification. Glassy carbon (Tokai Carbon Co. Ltd.) was cut into plates measuring $15 \times 15 \times 4 \mathrm{~mm}^{3}$. Prior to use, GC surfaces were polished with alumina slurries $(0.1$ then a $0.05 \mu \mathrm{m}$ particle size) on a polishing cloth (all Leco materials), with sonication in Milli-Q water for $5 \mathrm{~min}$ after each polishing step. Polished GC surfaces were sonicated in ACN for 5 min before use. An additional rinse in DCM or DMF was performed prior to photochemical modification.

Electrochemistry. All electrochemical measurements were performed at room temperature under $\mathrm{N}_{2}$ using computer-controlled EG \& G PAR model 362 and model 273A potentiostats or an Eco Chemie Autolab PGSTAT 302 potentiostat. Glassy carbon and PPF working electrodes were mounted horizontally on an insulated metal stage under a glass cell secured with four springs. A hole in the bottom of the cell was positioned on top of a Viton O-ring that sealed the solution above the sample. Electrical contact was maintained with a copper strip externally connected to the sample. The geometric area of the working electrodes was $0.22 \mathrm{~cm}^{2}$ for electrografting and $0.11 \mathrm{~cm}^{2}$ for subsequent electrochemical analysis of the modified surface. A standard threeelectrode cell was used. The counter electrode was a Pt wire, and the reference electrode for aqueous solutions was either saturated calomel (SCE) or $\mathrm{Ag} / \mathrm{AgCl}$, as indicated in the text. For nonaqueous solutions, the reference electrode was $\mathrm{Ag} / \mathrm{Ag}^{+}$ $\left(10^{-2} \mathrm{M} \mathrm{AgNO}_{3}\right.$ in $\left.0.1 \mathrm{M}\left[\mathrm{Bu}_{4} \mathrm{~N}\right] \mathrm{BF}_{4}-\mathrm{ACN}\right)$ and all potentials in $\mathrm{ACN}$ are given versus this reference. The hydroxymethylferrocene/ferrocenium $\left(\mathrm{FcOH} / \mathrm{FcOH}^{+}\right)$couple appeared at $E_{1 / 2}=$ $0.021 \mathrm{~V}$ versus $\mathrm{Ag} / 10^{-2} \mathrm{M} \mathrm{Ag}^{+}$. Voltammetric peak areas were estimated by fitting Lorentzian, Gaussian, or a mixture of Lorentzian-Gaussian curves to the peaks via the LevenbergMarquardt algorithm. Polynomial baseline corrections were made prior to curve fitting using Linkfit 4.1 software. ${ }^{38}$

Electrografting was performed in $0.1 \mathrm{M}\left[\mathrm{Bu}_{4} \mathrm{~N}\right] \mathrm{BF}_{4}-\mathrm{ACN}$ solutions containing $1 \mathrm{mM} \mathrm{NP} \mathrm{D}_{\mathrm{D}}$ or $5 \mathrm{mM} \mathrm{CB}_{\mathrm{D}}$ or $3 \mathrm{mM}$ solutions of TEG or PEG. NP $\mathrm{D}_{\mathrm{D}}$ was grafted using two scans from 0.3 to $-0.65 \mathrm{~V}$ at $100 \mathrm{mV} \mathrm{s}^{-1}$, followed by electrolysis at $E_{\mathrm{p}}-150 \mathrm{mV}$ for $300 \mathrm{~s} ; \mathrm{CB}_{\mathrm{D}}$ was grafted using two scans from 0.3 to $-0.80 \mathrm{~V}$ at $100 \mathrm{mV} \mathrm{s}^{-1}$, followed by electrolysis at $E_{\mathrm{p}}-150 \mathrm{mV}$ for $30 \mathrm{~s} .\left(E_{\mathrm{p}}\right.$ is the diazonium cation reduction peak potential obtained during the first scan.) TEG and PEG were electrografted using two initial

(37) Grabar, K. C.; Freeman, R. G.; Hommer, M. B.; Natan, M. J. Anal. Chem. 1995, 67, 735-743.

(38) Loring, J. S. Ph.D. Dissertation, University of California, Davis, CA, 2000. 
(a)

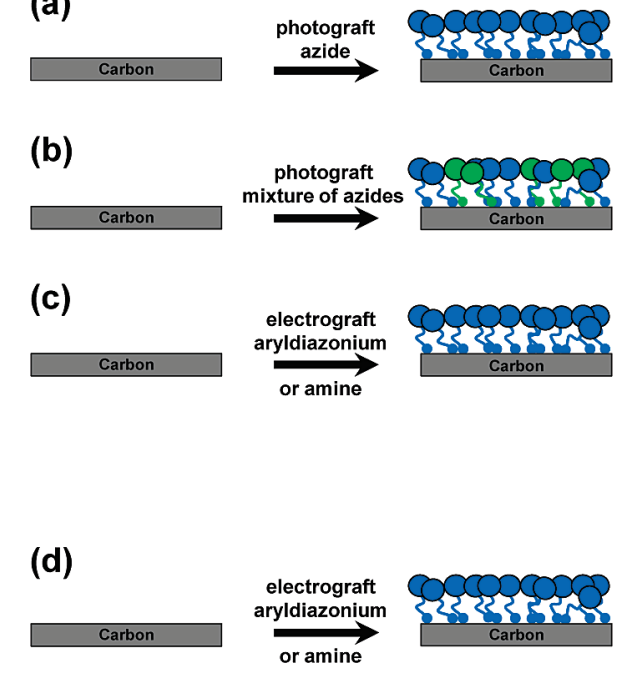

scans from 0 to $1.35 \mathrm{~V}$ at $100 \mathrm{mV} \mathrm{s}^{-1}$, followed by electrolysis at $1.35 \mathrm{~V}$ for $300 \mathrm{~s}$. After modification, all surfaces were sonicated in $\mathrm{ACN}$ for $10 \mathrm{~min}$ and dried in a stream of $\mathrm{N}_{2}$.

Photochemical Modification. For the standard photografting procedure, bare or film-modified carbon surfaces were spin coated with two coats of arylazide solution at $1000 \mathrm{rpm}$ for $30 \mathrm{~s}$. Solutions of $\mathrm{NP}_{\mathrm{A}}(200 \mathrm{mM})$ and $\mathrm{ITC}_{\mathrm{A}}(20 \mathrm{mM})$ were prepared in $\mathrm{DCM}$, and $\mathrm{AP}_{\mathrm{A}}(20 \mathrm{mM})$ was prepared in DMF. Nonpatterned surfaces were irradiated at $365 \mathrm{~nm}$ inside a Rayonet SrinivasanGriffin photochemical reactor (equipped with six $365 \mathrm{~nm}$ reaction lamp tubes, $\sim 1 \mathrm{~mW} \mathrm{~cm}^{-2}$ ) for $30 \mathrm{~min}$. To prepare patterned surfaces, samples were irradiated through a photomask in an inhouse-built photoreactor fitted with a $365 \mathrm{~nm}$ UV lamp (Philips HPR $125 \mathrm{~W}, 0.8 \mathrm{~mW} \mathrm{~cm} \mathrm{~cm}^{-2}$ ). The modified substrates were sonicated for $5 \mathrm{~min}$ in DCM or DMF and then for $5 \mathrm{~min}$ in acetone and dried in a stream of $\mathrm{N}_{2}$.

Postmodification Coupling Reactions. Glassy carbon samples derivatized with isothiocyanate groups were immersed in an aqueous solution of 4-nitrobenzoic hydrazide $(5 \mathrm{mM})$ for $30 \mathrm{~min}$ at room temperature with stirring. After reaction, the surfaces were sonicated for 2 min in DMF followed by 2 min in Milli-Q water. Amine-terminated surfaces were derivatized by immersion in a saturated DCM solution of 4-nitrobenzoyl chloride ( $200 \mathrm{mM})$ for $15 \mathrm{~h}$ with vigorous stirring. Postmodification sonication for 20 min in, successively, DCM, DMF, and Milli-Q water was necessary to remove unreacted species. Surfaces photografted with $\mathrm{NP}_{\mathrm{A}}$ were electrochemically reduced prior to coupling with an activated $N$-succinimidyl ester prepared by reacting $0.01 \mathrm{M}$ 4-nitrobenzoic acid with $1.2 \mathrm{~mol}$ equiv of DIPEA and TSTU in dry DMF for $3 \mathrm{~h}$ under $\mathrm{N}_{2}$. The reduction of $\mathrm{NP}_{\mathrm{A}}$ films was carried out in $\mathrm{H}_{2} \mathrm{SO}_{4}$ (concentration specified in text) at -0.7 versus $\mathrm{Ag} / \mathrm{AgCl}$ for $120 \mathrm{~s}$. The resulting amine groups were reacted with the activated $N$-succinimidyl ester solution for at least $24 \mathrm{~h}$ under $\mathrm{N}_{2}$. After coupling, the samples were sonicated for 5 min in DMF. Gold nanoparticles were assembled on bare and modified carbon surfaces by incubation in an as-prepared gold colloid solution for $20 \mathrm{~min}$ at room temperature in the dark. After immersion, the samples were rinsed with Milli-Q water and gently dried with $\mathrm{N}_{2}$.

Surface Characterization. Atomic force microscopy (AFM, Digital Instruments Dimension 3100) film thickness measurements on modified PPF surfaces were made as described previously. ${ }^{9}$ In brief, an AFM tip was used to scratch a section of film from the surface. From the cross-sectional profile of the scratch, the film thickness was determined. Unless stated otherwise, all quoted thickness data have an associated uncertainty of $\pm 0.2 \mathrm{~nm}$. This value includes the uncertainty arising from instrumental
(AFM) limitations, the variation in the depth of PPF removed when the film is scratched off of the surface, and the variation in the measured film thickness for replicate samples.

Scanning electron microscopy (SEM) images were recorded using either a 7000 HRSEM (JEOL) or a Raith 150 e-beam lithography system operating with 8 and $10 \mathrm{keV}$ accelerating voltages, respectively. Gold nanoparticles were counted by analyzing multiple SEM images obtained from different regions of a surface using ImageJ v1.37 software (Wayne Rasband, National Institutes of Health, Bethesda, MD).

Optical micrographs of condensation figures were obtained using an Olympus BX60 microscope equipped with a digital DP10 camera unit (Olympus). Condensation figures were obtained by delivering a small amount of water vapor to the carbon surface and immediately recording an image.

\section{Results and Discussion}

Figure 1 and Scheme 1 show, respectively, the surface modifiers and modification strategies investigated in this work. Arylazide derivatives $\mathrm{ITC}_{\mathrm{A}}$ and $\mathrm{AP}_{\mathrm{A}}$ were selected for study because their substituents give reactive groups for further coupling reactions. Nitrophenyl (NP) derivative $\mathrm{NP}_{\mathrm{A}}$ is convenient for characterization studies because the electroactivity of the NP group enables electrochemical monitoring of its surface concentration. Furthermore, NP groups are reduced in protic media to (mainly) aminophenyl groups, giving a useful tether layer. ${ }^{39}$ Table 1 lists surface concentration data for NP groups immobilized on the surface via different strategies, as described below. Both PPF and GC were used in initial characterization experiments. PPF has a very low surface roughness $(\leq 0.6 \mathrm{~nm})^{9}$ and hence is a useful substrate for film thickness measurements. However, each sample of PPF is used once only, and hence GC, which can be regenerated by polishing, is more convenient for other measurements.

Single-Component Surface Modification. The three arylazide derivatives, shown in Figure 1, were used for photografting directly onto PPF and GC (Scheme 1a). For convenience, as described above, a detailed examination of the grafted films was undertaken using $\mathrm{NP}_{\mathrm{A}}$. Solutions of $\mathrm{NP}_{\mathrm{A}}$ in $\mathrm{DCM}$ were spincoated onto GC and PPF surfaces and photolyzed at $365 \mathrm{~nm}$ for selected times. After sonication to remove weakly attached material, the samples were mounted in an electrochemical cell

(39) Yu, S. S. C.; Tan, E. S. Q.; Jane, R. T.; Downard, A. J. Langmuir 2007, 23 , 11074-11082. 
Table 1. Surface Concentration of NP Groups in Single and TwoComponent Films at GC from Photografting, Electrografting, and Coupling Reactions ${ }^{a}$

\begin{tabular}{|c|c|c|}
\hline \multirow[b]{2}{*}{ film } & \multirow[b]{2}{*}{ coupling reagent } & surface concentration \\
\hline & & $\left(\times 10^{-10} \mathrm{~mol} \mathrm{~cm}^{-2}\right)^{b}$ \\
\hline $\mathrm{NP}_{A}$ & none & $21.0(n=5)^{c}$ \\
\hline $\mathrm{NP}_{\mathrm{A}}^{d}$ & none & $5.8(n=3)$ \\
\hline $\mathrm{ITC}_{\mathrm{A}}$ & $\mathrm{NO}_{2 \text {-benzoic hydrazide }}$ & $4.1(n=1)$ \\
\hline $\mathrm{AP}_{\mathrm{A}}$ & $\mathrm{NO}_{2 \text {-benzoyl chloride }}$ & $2.7(n=3)$ \\
\hline $\mathrm{NP}_{\mathrm{A}}-\mathrm{AP}_{\mathrm{A}}$ & none & $5.5(n=1)$ \\
\hline TEG-NP & none & $3.1(n=3)$ \\
\hline TEG-NP ${ }^{e}{ }^{e}$ & $\mathrm{NO}_{2 \text {-benzoyl chloride }}$ & $1.7(n=1)$ \\
\hline $\mathrm{CB}_{\mathrm{D}}-\mathrm{AP}_{\mathrm{A}}$ & $\mathrm{NO}_{2 \text {-benzoic acid }}$ & $2.4(n=3)$ \\
\hline $\mathrm{NP}_{\mathrm{D}}$ & none & $30.0(n=3)$ \\
\hline $\mathrm{NP}_{\mathrm{D}}-\mathrm{AP}_{\mathrm{A}}$ & none & $26.6(n=3)$ \\
\hline \multicolumn{3}{|c|}{$\begin{array}{l}{ }^{a} \text { Preparation conditions are described in the text. }{ }^{b} \text { All surface } \\
\text { concentrations have an estimated uncertainty of } 20 \% \text { based on the } \\
\text { maximum observed RSD for repeated measurements. The error estimate } \\
\text { includes sample-to-sample reproducibility and curve fitting. }{ }^{c} n \text { is the } \\
\text { number of separate samples analyzed. }{ }^{d} \mathrm{NP}_{\mathrm{A}} \text { at PPF. }{ }^{e} \text { The TEG-NP } \\
\text { film was electroreduced in } 0.1 \mathrm{M} \mathrm{H}_{2} \mathrm{SO}_{4} \text { prior to the coupling reaction. }\end{array}$} \\
\hline
\end{tabular}

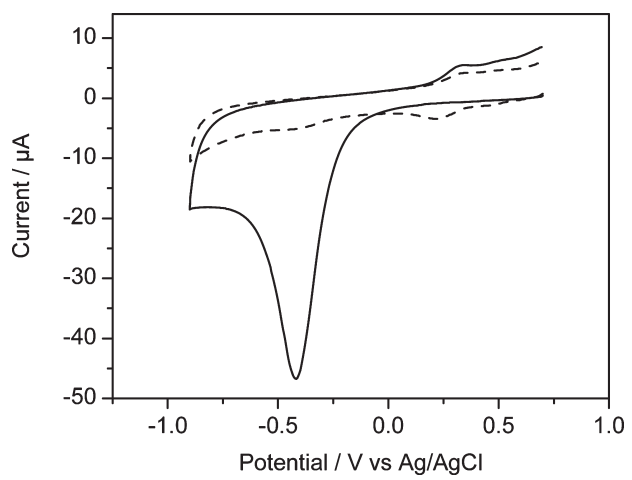

Figure 2. Two consecutive cyclic voltammograms in $0.1 \mathrm{M} \mathrm{H}_{2} \mathrm{SO}_{4}$ of a GC surface spin-coated with two layers of $200 \mathrm{mM} \mathrm{NP}$ followed by photolysis for $30 \mathrm{~min}$. The solid line represents the first scan; the dashed line represents the second scan.

for voltammetric analysis. Figure 2 shows two consecutive cyclic voltammograms in $0.1 \mathrm{M} \mathrm{H}_{2} \mathrm{SO}_{4}$ for a GC surface spin-coated with two layers of $200 \mathrm{mM} \mathrm{NP}_{\mathrm{A}}$, followed by photolysis for $30 \mathrm{~min}$. The first scan shows the characteristic, irreversible reduction $\left(E_{\mathrm{p}}=-0.40 \mathrm{~V}\right.$ vs $\left.\mathrm{Ag} / \mathrm{AgCl}\right)$ of the NP group to aminophenyl (eq 1) and hydroxyaminophenyl groups (eq 2) and, on the return scan, the oxidation $\left(E_{\mathrm{p}}=0.3 \mathrm{~V}\right.$ vs $\left.\mathrm{Ag} / \mathrm{AgCl}\right)$ of hydroxyaminophenyl to nitrosophenyl groups (eq 3 ). ${ }^{40}$ In the second cycle, the only significant feature is the nitrosophenyl/hydroxyaminophenyl redox couple.

$$
\begin{aligned}
& \text { surface } \cdots \mathrm{Ph}-\mathrm{NO}_{2}+6 \mathrm{H}^{+}+6 \mathrm{e}^{-} \\
& \quad \rightarrow \text { surface } \cdots \mathrm{Ph}-\mathrm{NH}_{2}+2 \mathrm{H}_{2} \mathrm{O} \\
& \text { surface } \cdot \mathrm{Ph}-\mathrm{NO}_{2}+4 \mathrm{H}^{+}+4 \mathrm{e}^{-} \\
& \rightarrow \text { surface } \cdots \mathrm{Ph}-\mathrm{NHOH}+\mathrm{H}_{2} \mathrm{O}
\end{aligned}
$$

surface $\cdots \mathrm{Ph}-\mathrm{NHOH} \leftrightarrow \operatorname{surface} \cdot \cdot \mathrm{Ph}-\mathrm{NO}+2 \mathrm{H}^{+}+2 \mathrm{e}^{-}$

These cyclic voltammograms demonstrate that the GC surface has been modified with an $\mathrm{NP}_{\mathrm{A}}$ film. When the procedure was

(40) Ortiz, B.; Saby, C.; Champagne, G. Y.; Belanger, D. J. Electroanal. Chem. 1998, 455, 75-81.
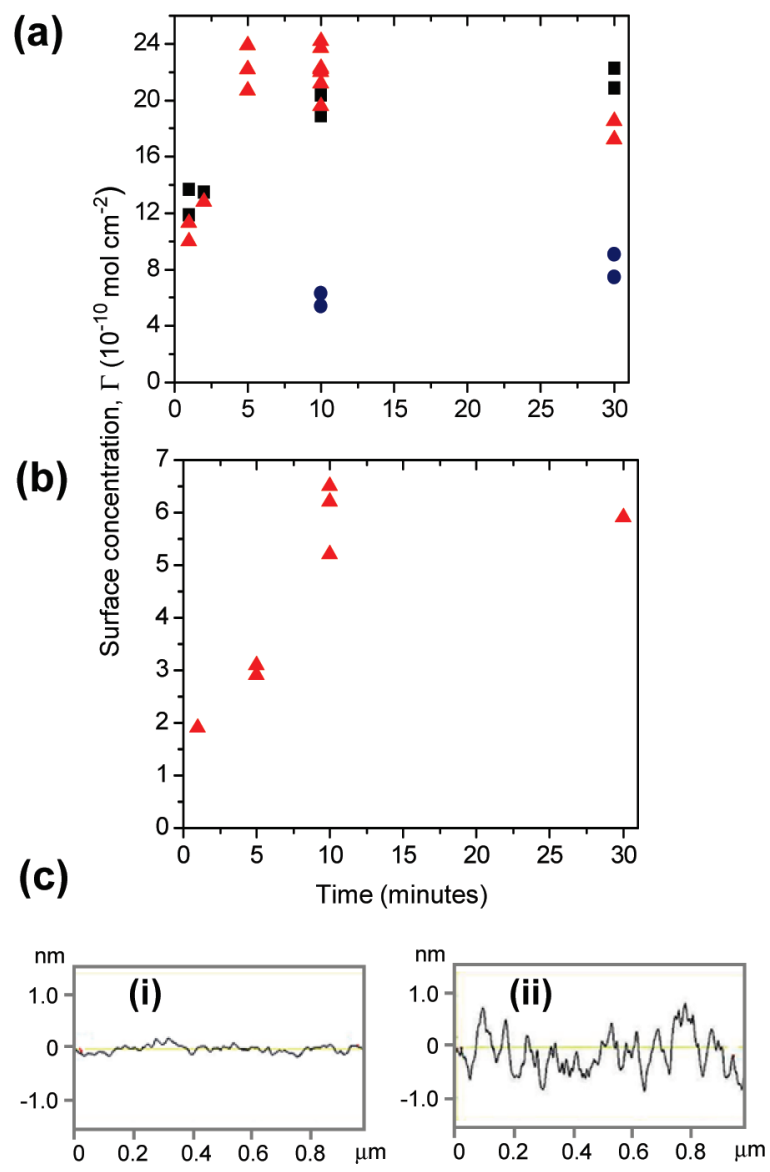

Figure 3. Surface concentrations of NP groups vs photolysis time at (a) GC after spin-coating solutions of $\mathrm{NP}_{\mathrm{A}}[20 \mathrm{mM}(\bullet), 100 \mathrm{mM}$ (口) and $200 \mathrm{mM}$ (red $\mathbf{\Delta}$ )] and (b) PPF after spin-coating a $200 \mathrm{mM}$ solution of $\mathrm{NP}_{\mathrm{A}}$. (c) AFM line profiles of PPF (i) before and (ii) after photografting with $\mathrm{NP}_{\mathrm{A}}$ using a photolysis time of $10 \mathrm{~min}$ and a $200 \mathrm{mM} \mathrm{NP}_{\mathrm{A}}$ spin-coating solution.

repeated without photolysis (spin-coated surfaces were stored in the dark for $30 \mathrm{~min}$ ), there was no evidence of the immobilization of NP groups.

The effects of photolysis time and concentration of the spincoating solution on the surface concentration of NP groups grafted to GC were examined, giving the data shown in Figure 3a. Surface concentrations of electroactive NP groups were estimated from the integrated charges associated with the NP reduction and hydroxyaminophenyl oxidation waves in the cyclic voltammograms (eqs $1-3$ and Figure 2). ${ }^{9}$ Figure 3 a shows that at all photolysis times, lower surface concentrations are obtained from the $20 \mathrm{mM} \mathrm{NP}_{\mathrm{A}}$ spin-coating solution than for the 100 and $200 \mathrm{mM}$ solutions and that the surface concentrations are the same for the 100 and $200 \mathrm{mM}$ solutions. Use of the latter spincoating solutions gives a maximum average surface concentration of $\sim 21 \times 10^{-10} \mathrm{~mol} \mathrm{~cm}^{-2}$, obtained for photolysis times of $5 \mathrm{~min}$ and longer (Table 1). When PPF is used as the substrate (Figure 3b), the maximum surface concentration of NP decreases to $\sim 5.8 \times 10^{-10} \mathrm{~mol} \mathrm{~cm}^{-2}$ (200 $\mathrm{mM} \mathrm{NP}_{\mathrm{A}}$ spin-coating solution). The lower surface concentration is undoubtedly in part due to the lower surface roughness of PPF compared to that of GC; however, the grafting yield may also be lower at PPF than at GC. ${ }^{41,42}$

(41) Brooksby, P. A.; Downard, A. J.; Yu, S. S. C. Langmuir 2005, 21, 11304 11311

(42) Garrett, D. J.; Lehr, J.; Miskelly, G. M.; Downard, A. J. J. Am. Chem. Soc. 2007, 129, 15456-15457. 

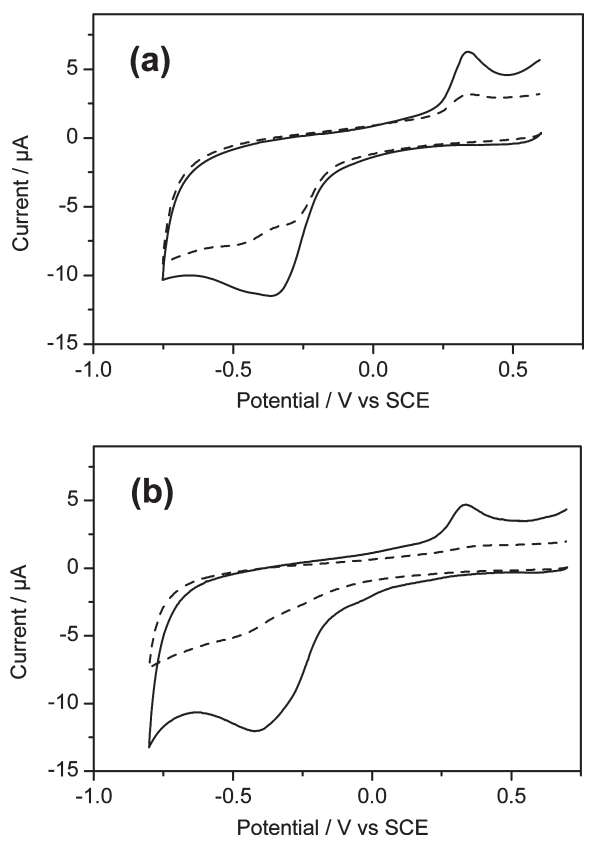

Figure 4. First scan cyclic voltammograms in (a) $0.1 \mathrm{M} \mathrm{H}_{2} \mathrm{SO}_{4}$ of GC photografted with $\mathrm{ITC}_{\mathrm{A}}(-)$ and polished GC (---) after reaction with 4-nitrobenzoic hydrazide and (b) in $0.25 \mathrm{M} \mathrm{H}_{2} \mathrm{SO}_{4}$ of GC photografted with $\mathrm{AP}_{\mathrm{A}}(-)$ and polished $\mathrm{GC}(---)$ after reaction with 4-nitrobenzoyl chloride.

A close-packed layer of NP groups on a flat surface has a calculated surface concentration ${ }^{43}$ of $\sim 12 \times 10^{-10} \mathrm{~mol} \mathrm{~cm}^{-2}$, and hence the $\mathrm{NP}_{\mathrm{A}}$ film on PPF is assumed to be loosely packed.

The thickness of the $\mathrm{NP}_{\mathrm{A}}$ films grafted to PPF surfaces after 10 min of photolysis (200 $\mathrm{mM} \mathrm{NP}_{\mathrm{A}}$ spin-coating solution) was measured by AFM depth profiling, giving an average thickness of $0.8 \pm 0.2 \mathrm{~nm}$. On the basis of the relevant molecular dimensions, a vertically aligned monolayer film of $\mathrm{NP}_{\mathrm{A}}$ has an expected height of $0.8 \mathrm{~nm}$. ${ }^{9}$ However, the AFM line profiles in Figure $3 \mathrm{c}$ show that, compared with bare PPF, the grafted PPF surface is very rough with peak-to-peak heights significantly greater than $0.8 \mathrm{~nm}$. Hence, these measurements support the formation of a loosely packed film with multilayer domains.

Photografting of $\mathrm{ITC}_{\mathrm{A}}$ and $\mathrm{AP}_{\mathrm{A}}$ to PPF was examined using $30 \mathrm{~min}$ of photolysis time and $20 \mathrm{mM}$ arylazide solutions for spincoating. Evidence of surface grafting was obtained from AFM measurements, which gave average film thicknesses of 1.0 and $0.8 \mathrm{~nm}$ for $\mathrm{ITC}_{\mathrm{A}}$ and $\mathrm{AP}_{\mathrm{A}}$, respectively. For both modifiers, AFM line profiles (not shown) were similar to that of $\mathrm{NP}_{\mathrm{A}}$, suggesting similar film structures. The use of higher-concentration arylazide solutions for spin-coating gave rougher layers, and hence the standard procedure used $20 \mathrm{mM}$ solutions of these azide derivatives. Additional tests were also carried out to confirm the attachment of the expected groups. The presence of isothiocyanate groups after grafting $\mathrm{ITC}_{\mathrm{A}}$ to $\mathrm{GC}$ was demonstrated indirectly by the reaction of a photografted surface with 4-nitrobenzoic hydrazide. After 30 min of reaction and cleaning by sonication, the electrode was transferred to an electrochemical cell. Figure $4 \mathrm{a}$ shows the first scans obtained in $0.1 \mathrm{M} \mathrm{H}_{2} \mathrm{SO}_{4}$ at the grafted electrode (-) and at a polished GC electrode (---) that had been incubated in 4-nitrobenzoic hydrazide under the same conditions. At both the grafted and polished GC electrodes, the irreversible reduction peak provides clear evidence of NP groups immobilized at the surface. Hydrazide reacts with surface

(43) Liu, Y.-C.; McCreery, R. L. J. Am. Chem. Soc. 1995, 117, 11254-11259. carbonyl groups invariably present on polished $\mathrm{GC} ;{ }^{44}$ however, after photografting with ITC $_{\mathrm{A}}$, the amount of NP coupled to the surface is significantly greater, consistent with the reaction of the hydrazide with grafted isothiocyanate groups.

The surface concentration of coupled NP groups at the $\mathrm{ITC}_{\mathrm{A}^{-}}$ grafted surface can be estimated from the voltammogram $(-)$ of Figure $4 \mathrm{a}$, giving a value of $\sim 4.1 \times 10^{-10} \mathrm{~mol} \mathrm{~cm}^{-2}$. This value is significantly less than the concentration of NP groups directly photografted to GC $\left(21 \times 10^{-10} \mathrm{~mol} \mathrm{~cm}^{-2}\right)$, which may indicate that $\mathrm{ITC}_{\mathrm{A}}$ has a lower photografting yield on GC than does $\mathrm{NP}_{\mathrm{A}}$. However, the similar AFM line profiles and average thicknesses of $\mathrm{ITC}_{\mathrm{A}}$ and $\mathrm{NP}_{\mathrm{A}}$ films on PPF suggest that their surface concentrations are similar. We have previously observed examples where coupling reactions at film-coated GC surfaces appear to be limited to the outermost layer(s), presumably because of permeability and steric effects within the films. ${ }^{39}$ In that work, the average ( $n$ (number of samples) $=4$ ) surface concentration of electroactive coupled NP groups was $(4.6 \pm 0.2) \times 10^{-10} \mathrm{~mol}$ $\mathrm{cm}^{-2}$, even though the underlying films had significantly higher concentrations of reactive groups. Hence we assume that the measured surface concentrations of coupled groups observed here do not accurately reflect the surface concentrations of reactive groups in the first layer. Nevertheless, the detection of coupled groups is a useful means of confirming the presence and reactivity of the first layer.

A similar approach was used to demonstrate the success of photografting $\mathrm{AP}_{\mathrm{A}}$ to the $\mathrm{GC}$ surface. Polished and $\mathrm{AP}_{\mathrm{A}}$-modified GC surfaces were reacted with 4-nitrobenzoyl chloride, and the resulting surfaces were examined by cyclic voltammetry. The characteristic response of coupled NP groups is evident in the voltammogram $(-)$ in Figure $4 \mathrm{~b}$ obtained at the photografted $\mathrm{AP}_{\mathrm{A}}$ surface in $0.25 \mathrm{M} \mathrm{H}_{2} \mathrm{SO}_{4}$. As found for the $\mathrm{ITC}_{\mathrm{A}}$ surface discussed above, the NP reduction peak is broad and the estimated surface concentration of NP groups is relatively low $\left(2.7 \times 10^{-10} \mathrm{~mol} \mathrm{~cm}^{-2}\right)$, presumably for the reasons outlined above. Figure $4 b$ (---) shows the voltammogram of a polished GC electrode reacted with 4-nitrobenzoyl chloride under the same conditions as for the $\mathrm{AP}_{\mathrm{A}}$-modified electrode. Trace amounts of NP groups indicated by the voltammogram are attributed to a small amount of physisorbed acid chloride that persists despite extensive cleaning of the surface by sonication (Experimental Section).

Two-Component Films from the Photolysis of Mixtures of Arylazides. Photolyzing mixtures of arylazides spin-coated onto the GC surface is a simple method of preparing mixed films. Surfaces modified with mixed films are particularly useful for biosensing applications because they can incorporate reactive tethers for coupling biomolecules and additionally a diluent component that serves to separate the tethers spatially and at the same time reduces nonspecific interactions with the surface. ${ }^{45,46}$ Coupling more than one component through selective reactions with different tether groups is another possibility with mixed films. ${ }^{47}$ To demonstrate the preparation of mixed films (Scheme 1b), a DCM/EtOH (50:50) solution of $\mathrm{NP}_{\mathrm{A}}(100 \mathrm{mM})$ and $\mathrm{AP}_{\mathrm{A}}(10 \mathrm{mM})$ was spin-coated and photolyzed as described in the Experimental Section. Cyclic voltammograms (not shown) of the photografted surfaces confirmed the presence of $\mathrm{NP}_{\mathrm{A}}$ groups with a surface concentration of $\sim 5.5 \times 10^{-10} \mathrm{~mol} \mathrm{~cm}{ }^{-2}$.

(44) Fryling, M. A.; Zhao, J.; McCreery, R. L. Anal. Chem. 1995, 67, 967-975. (45) Herne, T. M.; Tarlov, M. J. J. Am. Chem. Soc. 1997, 119, 8916-8920.

(46) Ladd, J.; Boozer, C.; Yu, Q. M.; Chen, S. F.; Homola, J.; Jiang, S. Langmuir 2004, 20, 8090-8095.

(47) Harper, J. C.; Polsky, R.; Wheeler, D. R.; Lopez, D. M.; Arango, D. C.; Brozik, S. M. Langmuir 2009, 25, 3282-3288. 
Table 2. Surface Concentration of Gold Nanoparticles at Single and Two-Component Films at GC from Photografting and Electrografting Procedures

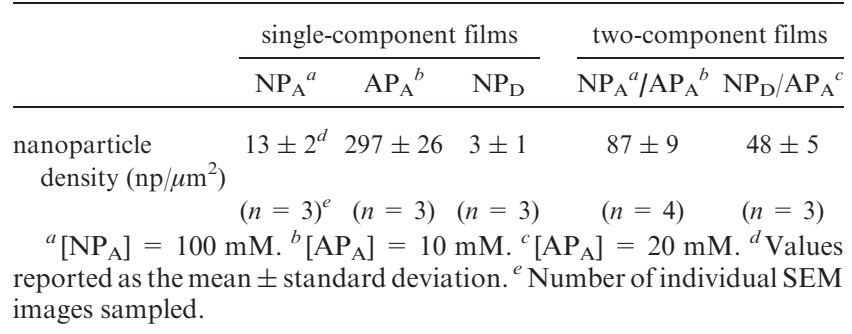

As expected, this value is significantly lower than that for singlecomponent $\mathrm{NP}_{\mathrm{A}}$ films, consistent with competition for surface sites during the photolysis of two-component mixtures. The successful grafting of $\mathrm{AP}_{\mathrm{A}}$ in the mixed film was confirmed in a second set of experiments. Following photografting and sonication cleaning, the modified substrates were incubated in a solution of citrate-capped gold nanoparticles for $20 \mathrm{~min}$. Single-component $\mathrm{NP}_{\mathrm{A}}$ and $\mathrm{AP}_{\mathrm{A}}$ films were also placed in the nanoparticle solution for the same length of time, and all samples were imaged by SEM. Nanoparticle counts at each type of modified surface are listed in Table 2; SEM images of the surfaces are shown in Figure S1 in Supporting Information. The data provide clear evidence for the presence of $\mathrm{AP}_{\mathrm{A}}$ groups in the mixed film, but unsurprisingly, the surface concentration of nanoparticles appears to be less than (approximately 29\%) that of single-component $\mathrm{AP}_{\mathrm{A}}$ films.

Two-Component Films by the Photografting of Arylazides to Film-Modified Surfaces. The photolysis of mixtures of arylazides, as described above, is the most straightforward approach to mixed films but is limited by the requirement that all modifiers must be soluble in the same solvent or solvent mixture. Spin-coating an arylazide solution onto a preformed film of the first modifier, followed by photolysis, is an alternative route to two-component films and does not have this limitation. Furthermore, in the two-step strategy, the first modifier can be immobilized by the photografting of arylazides but also by a variety of other methods, including the photolytic or thermal grafting of alkenes and alkynes, ${ }^{14-16,48}$ by electrochemical grafting from aryldiazonium salts, aliphatic amines, and arylacetates, ${ }^{3}$ or by spontaneous grafting at open-circuit potential from diazonium salts and aliphatic amines. ${ }^{2}$ This versatility greatly broadens the range of components that can be included on the surface. Another advantage of the two-step method is that it is easily adapted to surface patterning using standard photolithography techniques, as described in the next section.

To demonstrate the formation of mixed layers by sequential grafting, two-component films covering the whole surface were prepared and characterized (Scheme 1c). In the first example, $\mathrm{NP}_{\mathrm{A}}$ was photografted to a GC surface modified with a triethylene glycol (TEG) layer. This layer was electrografted to GC by the oxidation of TEG as described in the Experimental Section. $\mathrm{NP}_{\mathrm{A}}$ was spin-coated onto TEG-modified GC, and the surface was exposed to UV light for $30 \mathrm{~min}$. After cleaning by sonication, the sample was transferred to an electrochemical cell and cyclic voltammograms were obtained in $0.1 \mathrm{M} \mathrm{H}_{2} \mathrm{SO}_{4}$. The voltammograms of Figure $5 \mathrm{a}$ demonstrate that $\mathrm{NP}_{\mathrm{A}}$ groups (surface concentration $\sim 3.1 \times 10^{-10} \mathrm{~mol} \mathrm{~cm}{ }^{-2}$ ) are immobilized on the surface, but it is not clear where the groups are located. The

(48) Ssenyange, S.; Anariba, F.; Bocian, D. F.; McCreery, R. L. Langmuir 2005, $21,11105-11112$
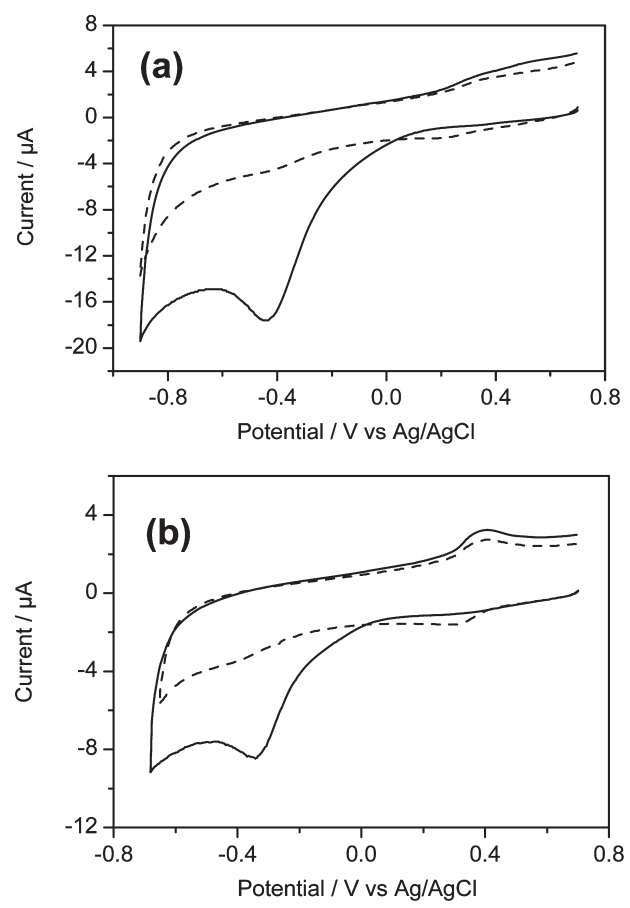

Figure 5. Two consecutive cyclic voltammograms in $0.1 \mathrm{M} \mathrm{H}_{2} \mathrm{SO}_{4}$ of (a) TEG-modified GC after photografting $\mathrm{NP}_{\mathrm{A}}$ and (b) the electrode in panel a after reduction and subsequent reaction with 4-nitrobenzoic acid. The solid line represents the first scan; the dashed line represents the second scan.

photogenerated nitrene is expected to be able to react with the TEG layer by insertion into $\mathrm{C}-\mathrm{H}$ bonds,${ }^{20}$ and it seems likely that $\mathrm{NP}_{\mathrm{A}}$ groups are grafted to both the TEG film and the GC surface. Considering this uncertainty, it is important to establish whether the aminophenyl and hydroxyaminophenyl groups generated by the reduction of $\mathrm{NP}_{\mathrm{A}}$ are accessible for further coupling reactions or, alternatively, are buried in the TEG layer. To examine this question, the reactivity of the aminophenyl and hydroxyaminophenyl groups with 4-nitrobenzoic acid was examined under conditions that promote amide bond formation (Experimental Section). Figure 5b shows cyclic voltammograms obtained in $0.1 \mathrm{M} \mathrm{H}_{2} \mathrm{SO}_{4}$ after the coupling reaction. There is clear evidence of the presence of NP groups (surface concentration $\sim 1.7 \times$ $10^{-10} \mathrm{~mol} \mathrm{~cm}^{-2}$ ), demonstrating the success of the reaction and establishing that the photografted groups are accessible and reactive.

In a second example using a similar approach, benzoic acid groups were first electrografted to the GC surface by the reduction of the corresponding diazonium cation, $\mathrm{CB}_{\mathrm{D}}$. Amine groups were added to the surface by spin-coating a solution of $\mathrm{AP}_{\mathrm{A}}$ onto the modified surface and photolyzing for $30 \mathrm{~min}$. To demonstrate the presence of the amine groups, an amide coupling reaction between nitrobenzoyl chloride and the film-based amine moieties was used to introduce NP groups onto the surface. Subsequent voltammetric analysis in $0.25 \mathrm{M} \mathrm{H}_{2} \mathrm{SO}_{4}$ showed a response very similar to that obtained for NP groups coupled, by the same method, to an $\mathrm{AP}_{\mathrm{A}}$ film directly grafted to $\mathrm{GC}$ (voltammogram not shown). For the two-component film, the estimated surface concentration of NP groups is $2.4 \times 10^{-10} \mathrm{~mol} \mathrm{~cm}{ }^{-2}$, compared with $2.7 \times 10^{-10} \mathrm{~mol} \mathrm{~cm}^{-2}$ for NP coupled to the single-component $\mathrm{AP}_{\mathrm{A}}$ film. This suggests that $\mathrm{AP}_{\mathrm{A}}$ groups have comparable reactivity on the two surfaces.

To investigate photografting reactions at modified surfaces further, a multilayer film of NP groups was electrografted 


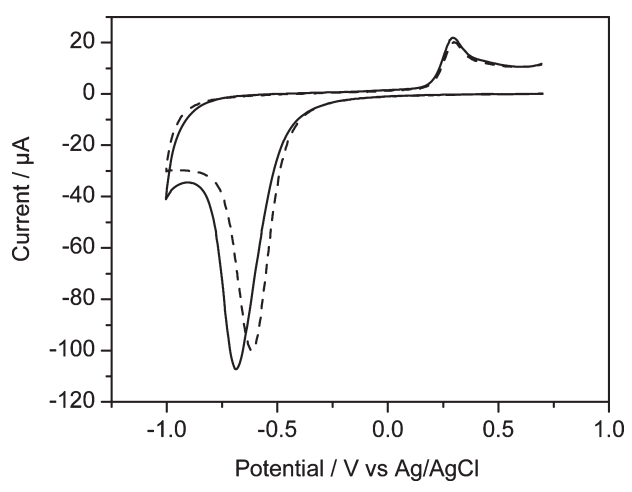

Figure 6. Cyclic voltammograms in $0.1 \mathrm{M} \mathrm{H}_{2} \mathrm{SO}_{4}$ of GC electrodes modified with (-) an electrografted $\mathrm{NP}_{\mathrm{D}}$ film and (---) an electrografted $\mathrm{NP}_{\mathrm{D}}$ film followed by a photografted $\mathrm{AP}_{\mathrm{A}}$ film.

onto $\mathrm{GC}$ from the corresponding diazonium salt and $\mathrm{AP}_{\mathrm{A}}$ was photografted to this surface from a spin-coated solution. The assembly of citrate-capped gold nanoparticles was examined at one set of two-component films and compared with the assembly at electrografted $\mathrm{NP}_{\mathrm{D}}$ films and $\mathrm{AP}_{\mathrm{A}}$ films directly photografted to GC using the same photolysis conditions as for the twocomponent films. The data in Table 2 show that after $20 \mathrm{~min}$ of immersion in the gold nanoparticle solution the surface coverage of nanoparticles at the two-component film is markedly greater than that at a single-component $\mathrm{NP}_{\mathrm{D}}$ film, confirming that $\mathrm{AP}_{\mathrm{A}}$ groups are immobilized at the surface by photografting. In a separate set of experiments, the electroactivity of the NP groups on the surface before and after the grafting of $\mathrm{AP}_{\mathrm{A}}$ was assessed. Figure 6 shows that the NP reduction peak areas for the two films are similar; however, the peak potential is shifted $\sim 80 \mathrm{mV}$ in the positive direction in the two-component film. This shift is tentatively attributed to the addition of electron-withdrawing protonated $\mathrm{AP}$ substituents to the $\mathrm{NP}_{\mathrm{D}}$ film. Importantly, the electroactivity of the $\mathrm{NP}_{\mathrm{D}}$ film is not measurably decreased after grafting $\mathrm{AP}_{\mathrm{A}}$, confirming that the method affords two-component films in which each component retains its usual activity.

These examples of mixed-film preparation demonstrate that the photografting of arylazides is a simple approach both to generating surfaces in which reactive tethers are incorporated in a nonreactive background film (as exemplified by grafting a mixed $\mathrm{NP}_{\mathrm{A}}$ and TEG layer) and to generating surfaces with two different reactive tethers for selective coupling to different targets (as demonstrated by the sequential grafting of a benzoic acid film and $\mathrm{AP}_{\mathrm{A}}$, and $\mathrm{NP}_{\mathrm{D}}$ and $\left.\mathrm{AP}_{\mathrm{A}}\right)$. Control of the relative amounts of each component in the film and the extension of the methods to the preparation of surfaces with more than two components should be straightforward via control of the composition of the solutions used for grafting.

Patterned Two-Component Surface Modification. Having established the utility of preparing two-component films by sequential grafting, the method was applied to the preparation of patterned surfaces. We note that Kuhr's group and others have previously reported patterned grafting of the azide derivative, photobiotin, directly onto GC surfaces, ${ }^{21-27}$ but our goal here is to prepare film-coated surfaces on which different areas have different surface properties and reactivity. Modifying the whole surface enables a higher degree of control of surface properties than can be achieved by modifying only part of the surface. The general strategy for patterning is shown in Scheme 1d. In the first step, the first modifier is deposited as a continuous layer on the surface. In the second step, a solution of arylazide is spin-coated onto the modified surface and the surface is exposed to UV light

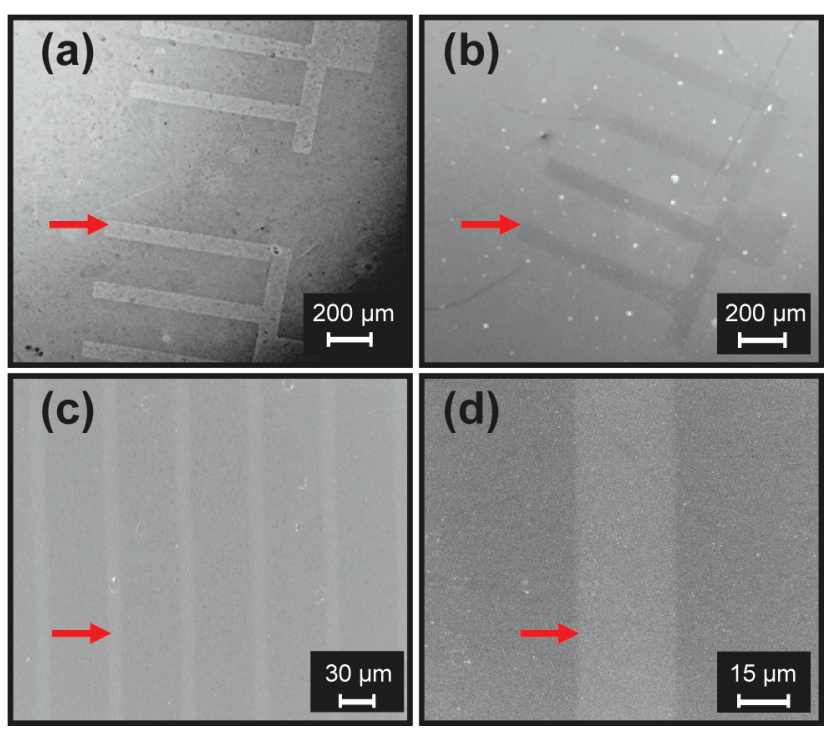

Figure 7. (a) Optical micrograph of a condensation figure obtained from an $\mathrm{NP}_{\mathrm{A}}$ film photopatterned onto a TEG film. (b) SEM image of an ITC $_{A}$ film photopatterned onto a PEG film. (c, d) SEM images of an $\mathrm{NP}_{\mathrm{A}}$ film photopatterned onto a $\mathrm{CB}_{\mathrm{D}}$ film. Arrows indicate the photografted component.

through a photomask. Activation of the arylazide occurs only in areas exposed to the light, and hence grafting occurs in these areas only. Figure 7 presents images of patterned surfaces prepared using three different film combinations. Figure 7a is an optical micrograph of a condensation figure ${ }^{49}$ obtained from a surface on which $\mathrm{NP}_{\mathrm{A}}$ was photopatterned onto an electrografted TEG film. The SEM image in Figure $7 \mathrm{~b}$ shows an electrografted methoxypoly(ethylene glycol)-amine (PEG) film photopatterned with ITC $_{A}$, and micrographs $c$ and $d$ show an electrografted $\mathrm{CB}_{\mathrm{D}}$ film photopatterned with $\mathrm{NP}_{\mathrm{A}}$. These examples demonstrate the preparation of surfaces that have a reactive tether patterned onto a background film designed to resist nonspecific protein adsorption $^{50}$ (Figure 7a,b) and a surface bearing spatially separated tethers with different reactivities (Figure 7c,d). All images clearly show the expected patterned areas and confirm that the sequential grafting method is readily adapted to preparing two-component patterned surfaces. In fact, the method can be extended to pattern any number of arylazide derivatives onto the surface, with a resolution dependent on the mask and/or optical patterning method used.

\section{Conclusions}

Photografting of arylazides to GC and film-modified surfaces by the photolysis of spin-coated samples at $365 \mathrm{~nm}$ in air is a simple and versatile method of surface modification. Films incorporating more than one modifier can be prepared using mixtures of arylazides or by photografting an arylazide modifier to a preformed film. The latter strategy has the advantage that the first film component can be grafted to the GC surface by any convenient method, giving very wide possibilities for the incorporation of desired organic functionalities on the surface. This strategy can also be readily adapted to patterning modifiers onto film-coated surfaces. For two-component films, both components

(49) Lopez, G. P.; Biebuyck, H. A.; Frisbie, C. D.; Whitesides, G. M. Science 1993, 260, 647-649.

(50) Mrksich, M.; Sigal, G. B.; Whitesides, G. M. Langmuir 1995, 11, 43834385 . 
534 retain their reactivity for further coupling reactions, indicating

535 that the method can be used to prepare multifunctional surfaces.

536 Acknowledgment. This work was supported by the MacDiar537 mid Institute for Advanced Materials and Nanotechnology. S.S.

538 C.Y. thanks the Tertiary Education Commission and A.J.G.

539 thanks the MacDiarmid Institute for doctoral scholarships. We thank Dr. John Loring for the use of Linkfit curve-fitting software.

Supporting Information Available: SEM images of gold nanoparticles assembled on modified GC surfaces. This material is available free of charge via the Internet at http://pubs.acs.org.
540

541

542 543 544 545 